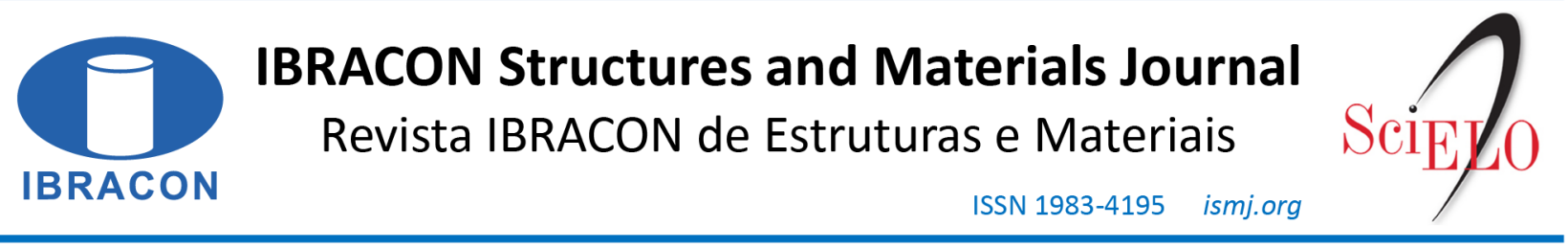

ORIGINAL ARTICLE

\title{
Nonlinear analysis method of concrete structures under cyclic loading based on the generalized secant modulus
}

\author{
Método para análise não linear de estruturas de concreto submetidas a \\ carregamentos cíclicos baseado no módulo secante generalizado \\ Lívia Ramos Santos Pereira ${ }^{\mathrm{a}}$ (i) \\ Samuel Silva Penna ${ }^{\mathrm{a}}$ (it)

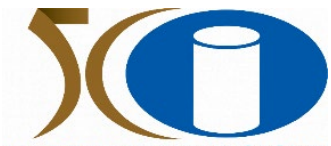 \\ YEARSIBRACON
}

${ }^{a}$ Universidade Federal de Minas Gerais - UFMG, Departamento de Engenharia de Estruturas, Belo Horizonte, MG, Brasil

Received 01 July 2021

Accepted 03 December 2021

\begin{abstract}
A smeared crack model to represent cyclic concrete behavior is presented in this work. The model is based on analytical and experimental studies from the literature and proposes a numerical approach using a new concept, the generalized secant modulus. The monotonic formulation is described, followed by the changes to include the cyclic response, and the stress-strain laws to reproduce the hysteresis. Simulations adopting the proposed model were compared with experimental tests of cyclic tension and compression available in the literature, resulting in consistent load cycles. Three-point bending was simulated to display the structural response under non-elementary load. Finally, a reinforced concrete beam was studied to evaluate the model performance under usual loadings. The results show the model capacity to reproduce cyclic analyses and its potential to be extended to general loadings.
\end{abstract}

Keywords: concrete, cyclic load, constitutive model, generalized secant modulus, stress-strain law.

Resumo: Um modelo de fissuração distribuída para representar o comportamento cíclico do concreto é apresentado neste trabalho. O modelo é baseado em estudos analíticos e experimentais presentes na literatura e propõe uma abordagem numérica utilizando um conceito novo, o módulo secante generalizado. A formulação monotônica é descrita, seguida pelas alterações para inclusão da resposta cíclica e pelas leis tensão-deformação para reproduzir a histerese. Simulações adotando o modelo proposto foram comparadas com ensaios experimentais de tração e compressão cíclicas disponíveis na literatura, resultando em uma representação consistente dos ciclos de carga. Uma flexão em três pontos foi simulada para exibir a resposta estrutural sob cargas não elementares. Por fim, uma viga de concreto armado foi estudada para avaliar o desempenho do modelo sob carregamentos usuais. Os resultados mostram a capacidade do modelo em reproduzir análises cíclicas e seu potencial de extensão a casos gerais de carregamento.

Palavras-chave: concreto, carga cíclica, modelo constitutivo, módulo secante generalizado, lei tensãodeformação.

How to cite: L. R. S. Pereira and S. S. Penna, "Nonlinear analysis method of concrete structures under cyclic loading based on the generalized secant modulus," Rev. IBRACON Estrut. Mater., vol. 15, no. 4, e15406, 2022, https://doi.org/10.1590/S1983-41952022000400006

\section{INTRODUCTION}

The complete description of a concrete structure subjected to mechanical loadings demands constitutive models capable of representing loading, unloading, and reloading regimes. Even under monotonic loading, the structural equilibrium can result in a stress redistribution related, e.g., to microcrack nucleation [1]. In other situations, the external load solicitation is cyclic [2]. Thus, cyclic constitutive models are required to represent the structural behavior. 
The literature presents a variety of constitutive models for quasi-brittle materials, as concrete, standing out the smeared crack models [3]-[6] and the damage models [7]-[9]. Nevertheless, most of them are restricted to monotonic behavior. A complete constitutive model must also cover the unloading/reloading regimes. Sinha et al. [10] and Karsan and Jirsa [11] were the pioneers in cyclic models, whose works motivated further studies [1], [12],[13].

Sima and Molins [14] proposed a constitutive model for concrete subjected to cyclic loadings in compression and tensile. A smeared crack approach is adopted to describe the strength and stiffness degradation. Because of the different properties of concrete under tensile and compression, two independent damage parameters were introduced to this model. Another improvement in the loop's representation is related to the dependency between the cyclic variables and the damage level in the envelope curve. Later, Breccolotti et al. [15] extended such a model, including special conditions to represent incomplete unload and reload paths.

Another numerical strategy that considers the distinct behavior of concrete under tensile and compression was developed by Feng et al. [16]. The authors analyzed the cyclic behavior in precast concrete structures, using a damage mechanics-based model to describe hysteresis in the effective stress space. Then, the effective stress is divided into tensile and compression parts, and the Helmholtz free energy is applied. The plastic strain evolution is based on an empirical model, while the energy release rates limit the damage evolution.

Alva et al. [17] also proposed a cyclic model based on damage. This research presents a numerical strategy formulated from the Lumped Damage Mechanics. Such an approach concentrates the dissipation of energy in hinges at the ends of the structural members. For cyclic action, an additional damage parameter is demanded, determined by experimental tests. The study by Chen et al. [18], on the other hand, is restricted to hysteresis loops in tensile tests, and a statistical damage model is the used method to represent the cyclic loading.

Besides the damage models, other numerical strategies are available in the literature. Moharrami and Koutromanos [19] developed an elastoplastic formulation to reproduce cyclic loading. A crack criterion is adopted to verify the degradation, while a return mapping algorithm calculates the stress update. For Mourlas et al. [20], the decomposition of the stress-strain relationship into hydrostatic and deviatoric components identifies the load loops. Li and Ren [21] proposed a modified version of the Chinese Standard Model: Code for design concrete structures, replacing the unloading/reloading single line path with two different tracks. The unloading path was reformulated to fit studies that show it has a curve shape.

Although the diversity of models to reproduce concrete cyclic behavior, most of them are restricted to fixed cyclic shapes, limiting their representation capacity. The current paper presents a formulation based on the approach of Lee et al. [22] to overcome this drawback and become the cyclic analysis more practical and general. The study by Lee et al. [22] is highlighted because of its simplicity and ease of application in the computational context. The authors developed an analytical method to obtain a material elastic modulus used for mapping the load loops. This method is based on the focal point concept, a pole that controls the unloading/reloading regimes, dividing the total strain into elastic and permanent parts.

In this paper, the methodology by Lee et al. [22] is incorporated into a smeared crack model, providing a variety of load cycles shapes. A mathematical formulation permitted the coupling among the elastic degradation model, the stressstrain total relation, and the generalized secant modulus to represent degradation and plastification. The stress-strain laws are an essential part of the proposed method. However, most well-known laws [23]-[26] are restricted to the monotonic curve. Unloading/reloading stress-strain relations were added into the constitutive model to cover this gap. It is presented four cyclic strategies: the secant, the elastic, the linear path based on the focal point [22], [27], and the nonlinear hypothesis by Popovics-Saenz [28]-[31]. Numerical simulations of structures under cyclic loads in a plane stress state have been simulated via the Finite Element Method (FEM) to validate this model.

\section{ELASTIC DEGRADATION MODEL APPLIED TO CYCLIC ANALYSIS}

The nonlinear cyclic analysis is a quasi-static analysis with load increase/decrease. Under a hysteretic state, the material has a nonlinear behavior, and load loops are observed in structural response. In concrete structures, the nonlinearity comes from material degradation. A common choice to represent such a process is the smeared crack models. In this paper, the model proposed by Penna [32] has been extended to include cyclic simulations.

A load script is required to reproduce hysteresis by operating the loading sign. The standard Newton-Raphson method controls the loading evolution, and the incremental load depends on a control method. The direct displacement method [33] was adopted. This strategery favors the cycle monitoring, directly changing the sign of the degree of freedom controlled.

Although the current work aims to reproduce cyclic loads, the fatigue process is not addressed. Fatigue is related to repetitive loads and a significant number of cycles, causing structural collapse even under stresses lower than the 
material strength. The present paper studies the cyclic reproduction in the softening branch (post-peak) of the equilibrium path.

\subsection{Smeared crack model}

Since the 1960s, constitutive models have been developed to describe concrete cracking [3], [34]. The smeared crack models consider phenomenological hypotheses to obtain concrete degradation. Initially regarded as linear, elastic, homogeneous, and isotropic, the material medium can become nonlinear, inelastic, and orthotropic under mechanical loads. The homogeneity, on the other hand, is preserved. In these models, the elastic material properties are modified considering the orthotropic directions to reproduce the deterioration. These changes depend on the material stress/strain state [35], [36]. Consequently, such models are also known as elastic degradation models [37]-[39].

A wide variety of these models could be found in Penna [32], including the monotonic smeared crack model. Such model is based on total strains, and a secant (represented by the superscript s) constitutive relation computes the stresses. The principal strain directions are the local crack system (referred by $\ell$ ), i.e., the evaluation of the material properties considers the directions normal and tangential to the crack plane to compose the constitutive tensor. Such a tensor can assume different forms [40], including the plane stress state matrix of Equation 1.

$$
\left[{ }_{\ell}^{s} \mathrm{D}\right]=\left[\begin{array}{lll}
{ }_{\ell}^{s} \mathrm{D}_{11} & { }_{\ell}^{\mathrm{s}} \mathrm{D}_{12} & { }_{\ell}^{\mathrm{s}} \mathrm{D}_{13} \\
{ }_{\ell}^{\mathrm{s}} \mathrm{D}_{21} & \mathrm{~s}_{\ell} \mathrm{D}_{22} & { }_{\ell}^{\mathrm{s}} \mathrm{D}_{23} \\
{ }_{\ell}^{s} \mathrm{D}_{31} & { }_{\ell}^{s} \mathrm{D}_{32} & { }_{\ell}^{s} \mathrm{D}_{33}
\end{array}\right]=\frac{1}{1-\frac{\mathrm{E}_{\mathrm{n}} \mathrm{E}_{\mathrm{t}}}{\mathrm{E}_{0}^{2}} v^{2}}\left[\begin{array}{ccc}
\mathrm{E}_{\mathrm{n}} & \frac{v \mathrm{E}_{\mathrm{n}} \mathrm{E}_{\mathrm{t}}}{\mathrm{E}_{0}} & 0 \\
\frac{v \mathrm{E}_{\mathrm{n}} \mathrm{E}_{\mathrm{t}}}{\mathrm{E}_{0}} & \mathrm{E}_{\mathrm{t}} & 0 \\
0 & 0 & \left(1-\frac{\mathrm{E}_{\mathrm{n}} \mathrm{E}_{\mathrm{t}}}{\mathrm{E}_{0}^{2}} v^{2}\right) \mathrm{G}_{\mathrm{nt}}
\end{array}\right]
$$

where $\mathrm{E}_{0}$ is the Young modulus, $\mathrm{v}$ is the Poisson coefficient, and $\mathrm{n}$ and $\mathrm{t}$ are the material orthotropic directions: $\mathrm{n}$ is the normal direction, and $t$ is the tangential direction to the crack plane. $G_{n t}$ is the shear modulus, calculated by Equation 2 .

$$
G_{n t}=\frac{E_{0} E_{n} E_{t}}{E_{0} E_{n}+E_{0} E_{t}+2 v E_{n} E_{t}}>\beta_{r} G_{0}(2)
$$

where $\beta_{r}$ is the shear retention factor and $G_{0}$ is the shear modulus of the undamaged material.

Then, the secant moduli are calculated in function of the principal strains. At this point, stress-strain laws are required to obtain the elastic modulus degradation. Particular relations may be necessary to represent the concrete behavior under tension and compressive loads.

The total relation for the stress state calculation is symbolically written by Equation 3 .

$$
\left\{\sigma_{\ell}\right\}=\left[{ }_{\ell}^{\mathrm{s}} \mathrm{D}\right] .\left\{\varepsilon_{\ell}\right\} .
$$

Or, in the matrix form, by Equation 4.

$$
\left\{\begin{array}{c}
\sigma_{n} \\
\sigma_{t} \\
\tau_{n t}
\end{array}\right\}=\frac{1}{1-\frac{E_{n} E_{t}}{E_{0}^{2}} v^{2}}\left[\begin{array}{ccc}
E_{n} & \frac{v E_{n} E_{t}}{E_{0}} & 0 \\
\frac{v E_{n} E_{t}}{E_{0}} & E_{t} & 0 \\
0 & 0 & \left(1-\frac{E_{n} E_{t}}{E_{0}^{2}} v^{2}\right) G_{n t}
\end{array}\right]\left\{\begin{array}{c}
\varepsilon_{n} \\
\varepsilon_{t} \\
\gamma_{n t}
\end{array}\right\},(4)
$$

where $\sigma_{n}, \sigma_{t}$ and $\tau_{n t}$ are the stress components, while $\varepsilon_{n}, \varepsilon_{t}$ and $\gamma_{n t}$ are the strain components in the local crack system.

In an iterative-incremental solution based on the standard Newton-Raphson method, the tangential constitutive relation is also required, derived from the total relation, as expressed by Equation 5. 
$\left[{ }_{\ell}^{\mathrm{t}} \mathrm{D}\right]=\frac{\partial\left\{\sigma_{\ell}\right\}}{\partial\left\{\varepsilon_{\ell}\right\}}=\left[{ }_{\ell}^{\mathrm{s}}[\mathrm{D}]+\frac{\left.\partial{ }_{\ell}^{\mathrm{s}} \mathrm{D}\right]}{\partial\left\{\varepsilon_{\ell}\right\}}\left\{\varepsilon_{\ell}\right\}\right]$

where $\frac{\partial\left[\left[_{\ell}^{S} \mathrm{D}\right]\right.}{\partial\left\{\varepsilon_{\ell}\right\}}\left\{\varepsilon_{\ell}\right\}$ is calculated with Equation 6.

$\frac{\partial\left[{ }_{\ell}^{\mathrm{s}} \mathrm{D}\right]}{\partial\left\{\varepsilon_{\ell}\right\}}\left\{\varepsilon_{\ell}\right\}=\left[\begin{array}{ccc}\frac{\partial_{1}^{\mathrm{s}} \mathrm{D}_{11}}{\partial \varepsilon_{\mathrm{n}}} \varepsilon_{\mathrm{n}}+\frac{\partial \mathrm{D}_{12}}{\partial \varepsilon_{\mathrm{n}}} \varepsilon_{\mathrm{t}} & \frac{\partial_{1}^{\mathrm{s}} \mathrm{D}_{11}}{\partial \varepsilon_{\mathrm{t}}} \varepsilon_{\mathrm{n}}+\frac{\partial \mathrm{D}_{12}}{\partial \varepsilon_{\mathrm{t}}} \varepsilon_{\mathrm{t}} & 0 \\ \frac{\partial_{1}^{\mathrm{s}} \mathrm{D}_{21}}{\partial \varepsilon_{\mathrm{n}}} \varepsilon_{\mathrm{n}}+\frac{\partial \mathrm{D}_{22}}{\partial \varepsilon_{\mathrm{n}}} \varepsilon_{\mathrm{t}} & \frac{\partial_{1}^{\mathrm{s}} \mathrm{D}_{21}}{\partial \varepsilon_{\mathrm{t}}} \varepsilon_{\mathrm{n}}+\frac{\partial \mathrm{D}_{22}}{\partial \varepsilon_{\mathrm{t}}} \varepsilon_{\mathrm{t}} & 0 \\ 0 & 0 & 0\end{array}\right] .(6)$

The model was presented in the local system. The formulation in global systems is given by Equation 7 and Equation 8 .

$$
\left\{\sigma_{\ell}\right\}=\left[T_{\sigma}\right]\left\{\sigma_{g}\right\}(7),\left\{\varepsilon_{\ell}\right\}=\left[T_{\varepsilon}\right]\left\{\varepsilon_{g}\right\} .(8)
$$

Where $\left\{\sigma_{g}\right\}$ is the global stress vector, $\left\{\varepsilon_{g}\right\}$ is the global strain vector, $\left[T_{\sigma}\right]$ and $\left[T_{\varepsilon}\right]$ are the stress and the strain transformation matrices, respectively.

Thus, by replacing Equation 7 and Equation 8 in Equation 3, the Equation 9 is determined.

$\left[T_{\sigma}\right]\left\{\sigma_{g}\right\}=\left[{ }_{\ell}^{s} D\right]\left[T_{\varepsilon}\right]\left\{\varepsilon_{g}\right\} .(9)$

Isolating $\left\{\sigma_{g}\right\}$ in Equation 9, the global stress vector is expressed as Equation 10.

$\left\{\sigma_{g}\right\}=\left[T_{\sigma}\right]^{-1}\left[{ }_{\ell}^{s} D\right]\left[T_{\varepsilon}\right]\left\{\varepsilon_{g}\right\}$.

Since the global matrix is given by Equation 11

$\left[{ }_{g}^{s} D\right]=\left[T_{\sigma}\right]^{-1}\left[{ }_{\ell}^{s} D\right]\left[T_{\varepsilon}\right],(11)$

the total relation in the global system is written by Equation 12 .

$\left\{\sigma_{g}\right\}=\left[{ }_{g}^{s} D\right]\left\{\varepsilon_{g}\right\}$

The global tangent operator comes from the derivative of total relation in the global system to the strain vector, resulting in Equation 13.

$$
\left[{ }_{g}^{t} D\right]=\frac{\partial\left\{\sigma_{g}\right\}}{\partial\left\{\varepsilon_{g}\right\}}=\left[{ }_{g}^{s} D\right]+\left[T_{\varepsilon}\right]^{T} \frac{\partial\left[{ }_{\ell}^{s} D\right]}{\partial\left\{\varepsilon_{\ell}\right\}}\left\{\varepsilon_{\ell}\right\}\left[T_{\varepsilon}\right]+\frac{\partial\left[T_{\varepsilon}\right]^{T}}{\partial \theta}\left\{\sigma_{\ell}\right\}\left(\frac{\partial \theta}{\partial\left\{\varepsilon_{g}\right\}}\right)^{T},
$$

where $\theta$ is the angle direction of the local crack system.

If the local system is fixed during the crack nucleation, the transformation matrix does not present variation. Consequently, the global tangent matrix can be defined as Equation 14. 


$$
\left[{ }_{g}^{t} D\right]=\frac{\partial\left\{\sigma_{g}\right\}}{\partial\left\{\varepsilon_{g}\right\}}=\left[{ }_{g}^{s} D\right]+\left[T_{\varepsilon}\right]^{T} \frac{\partial\left[{ }_{\ell}^{s} D\right]}{\partial\left\{\varepsilon_{\ell}\right\}}\left\{\varepsilon_{\ell}\right\}\left[T_{\varepsilon}\right]
$$

The secant modulus monitoring can establish the loading regime. Although, a more efficient control method based on loading functions is adopted. The loading functions are expressed in terms of strain components $\left(\varepsilon_{n}, \varepsilon_{t}\right)$ by Equation 15 and Equation 16.

$$
f_{n}=\varepsilon_{n}-\kappa_{n},(15) f_{t}=\varepsilon_{t}-\kappa_{t} .(16)
$$

Where $f_{n}$ and $f_{t}$ are, respectively, the loading function in the normal and tangential directions to the crack plane; $\varepsilon_{n}$ and $\varepsilon_{t}$ are the strain components; $\kappa_{n}$ and $\kappa_{t}$ are historical parameters, i.e., the maximum values of $\varepsilon_{n}$ and $\varepsilon_{t}$ during the analysis. The initial values of the historical parameters $\left(\kappa_{0 n}, \kappa_{0 t}\right)$ represents the strain in the elastic limit. When $\kappa_{0 n}$ or $\kappa_{0 t}$ are exceeded, the degradation starts, and the material behavior turns inelastic in this direction.

Regarding the loading regime, the loading function variation $(\dot{f})$ and the historical variable evolution $(\dot{\kappa})$ are calculated by Equation 17 and Equation 18, respectively, in a pseudo-time of the iterative-incremental process.

$$
\dot{f}=f_{(t)}-f_{(t-1)},(17) \dot{\kappa}=\kappa_{(t)}-\kappa_{(t-1)}
$$

Where $(t)$ and $(t-1)$ represent the current and the previous moments, respectively.

At last, the Kuhn-Tucker conditions are applied to identify the loading regime: elastic loading $(f<0 ; \dot{f}>0 ; \kappa=$ $\left.\kappa_{0} ; \dot{\kappa}=0\right)$; inelastic loading $\left(f=0 ; \dot{f}=0 ; \kappa>\kappa_{0} ; \dot{\kappa}>0\right)$; unloading $\left(f<0 ; \dot{f}<0 ; \kappa>\kappa_{0} ; \dot{\kappa}=\right.$ $0)$; and reloading $\left(f<0 ; \dot{f}>0 ; \kappa>\kappa_{0} ; \dot{\kappa}=0\right)$.

Since the regimes are known, the secant moduli $\left(E_{n}, E_{t}\right)$ can be calculated by stress-strain laws. Such moduli reproduce the material degradation and are part of the constitutive matrix that provides the stress. In cyclic analyses, the secant moduli need to be reformulated for the unloading/reloading. Nevertheless, the historical variables remain the same during hysteresis.

A change in the constitutive matrix (Equation 1) has been proposed to perform the cycles. The generalized secant moduli $E_{G S n}, E_{G S t}$ replaces the traditional secant moduli $E_{n}, E_{t}$ in unloading/reloading stages. The stress-strain laws that provide the secant moduli must also be redefined to include cyclic paths and the $E_{G S}$ calculation. Figure 1 summarizes the process.

\subsection{Stress-strain laws for cyclic loading}

The constitutive models are mechanical-mathematics representations that describe the behavior of a material media. The degradation is computed by the secant modulus variation for the proposed model, using stress-strain laws defined from approximations of experiments. Such laws can assume different formats: linear, polynomial, exponential, among others.

Besides the traditional approximations, concrete stress-strain laws for tension and compression loadings are highlighted. Some of them were proposed by Carreira and Chu [23, 24] (Equation 19), Boone et al. [25], and Bone and Ingraffea [26] (Equation 20).

$$
\sigma=f_{i} \frac{k\left(\varepsilon / \varepsilon_{i}\right)}{k-1+\left(\varepsilon / \varepsilon_{i}\right)^{k}}, \text { where } k=\frac{1}{1-\left(f_{i} / \varepsilon_{i} \cdot E_{0}\right)} \text { and } i=t, c .
$$

$\sigma$ is the stress, $f_{i}$ is the strength limit, $\varepsilon_{i}$ is the strain related with the elastic limit, $\varepsilon$ is the current strain, and $i=t$ represents tension, while $i=c$ represents compression.

$$
\sigma=f_{t} e^{-k\left(\varepsilon-\varepsilon_{t}\right)}, \text { with: } k=h f_{t} / G_{f}
$$


Where $\sigma$ is the stress, $f_{t}$ is the tensile strength, $\varepsilon$ is the current strain, $\varepsilon_{t}$ is the strain in the elastic tension limit, $h$ is the characteristic length, and $\mathrm{G}_{\mathrm{f}}$ is the fracture energy.

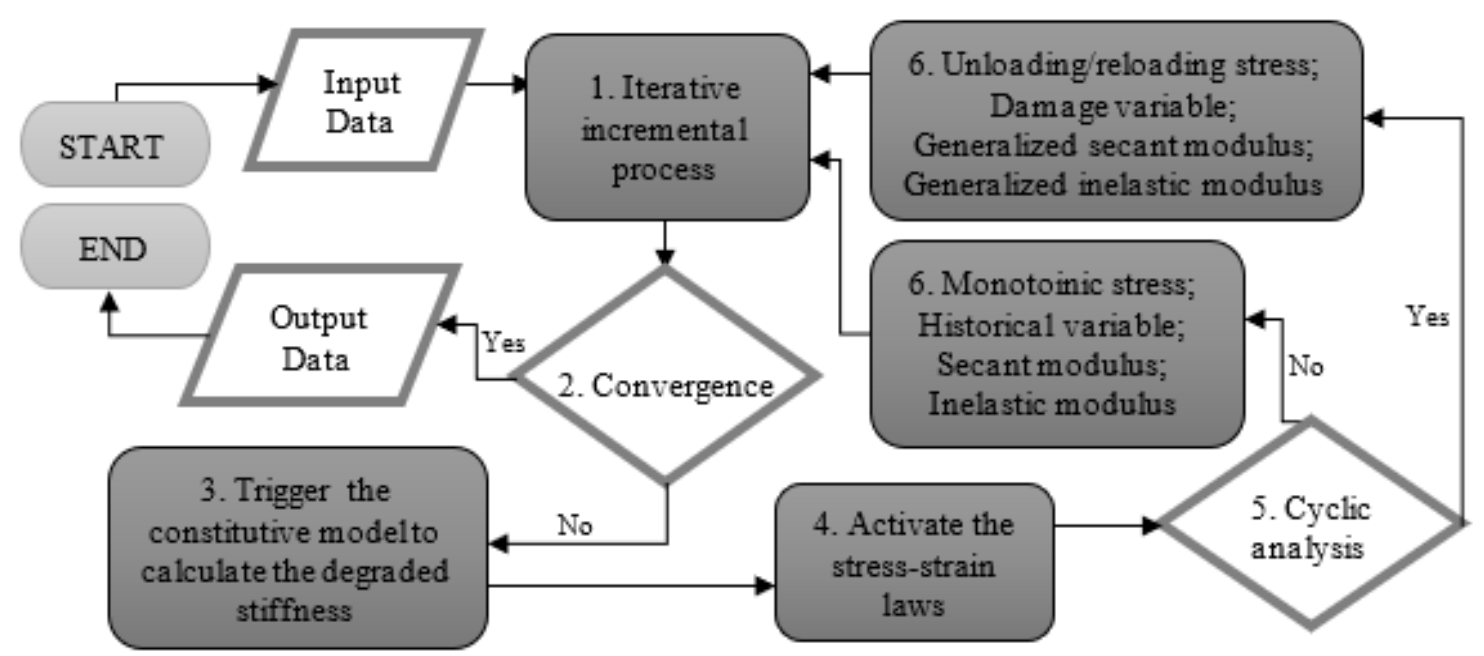

Figure 1. Cyclic analysis process.

The stress-strain relations, although are restricted to monotonic loadings. In this work, four hypotheses have been incorporated in the original laws to reproduce the load cycles: the secant cycle, based on the traditional secant modulus; the linear cycle, using the undamaged elastic modulus; the linear cycle based on focal point concept; and an extended version presented by Bono [29] of the law initially proposed by Popopovics-Saenz. All cyclic strategies adopted the generalized secant modulus proposal detailed as follows.

\subsubsection{Secant unloading/reloading}

The secant hypothesis is the most common representation of concrete behavior because of its simplicity and precision in reproducing monotonic loadings. Another relevant feature is the maximum strain and the current material degradation monitoring. The degraded modulus can be calculated as the straight slope that starts in origin and goes until the unloading point. Figure 2 illustrates the secant hypothesis. The point with coordinates $\varepsilon_{\mathrm{r}}, \sigma_{\mathrm{r}}$ is a generic point where the reloading begins, that is the origin of the system $\sigma-\varepsilon$ for a complete cycle.

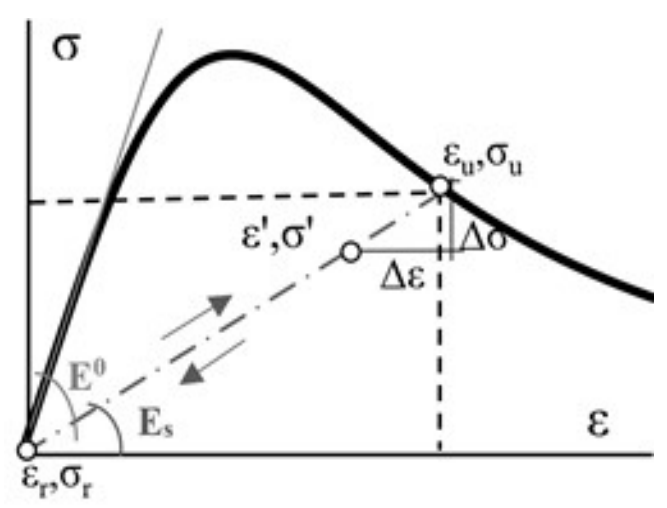

Figure 2. Secant unloading/reloading. 


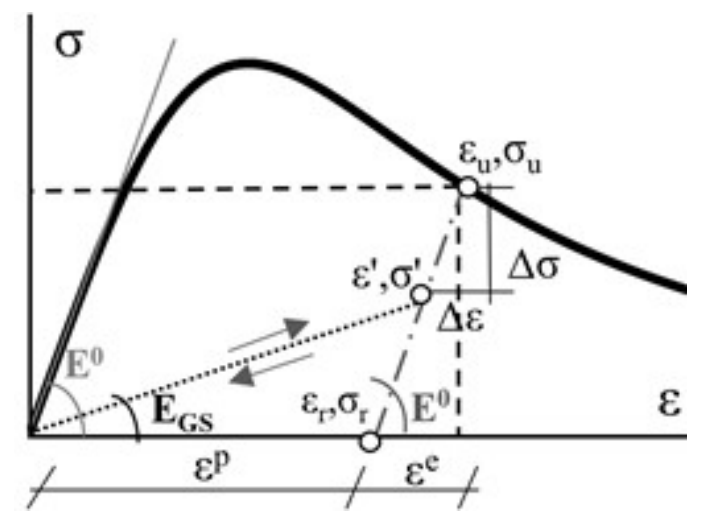

Figure 3. Linear elastic unloading/reloading.

The secant modulus Es is given by the stress-strain law as Equation 21.

$$
E_{s}=\sigma\left(\varepsilon_{u}\right) / \varepsilon_{u}
$$

Where the unloading strain $\left(\varepsilon_{\mathrm{u}}\right)$ is the maximum strain the material has ever experienced, the historical parameter. Despite the simplicity, the secant strategy loses representativity during cycles with an advanced strain stage since the permanent strains are not considered.

\subsubsection{Linear elastic unloading/reloading}

The linear elastic approach is based on the undamaged elastic modulus $\left(\mathrm{E}_{0}\right)$, as shown in Figure 3. The cycle is simplified by a straight line whose slope is $\mathrm{E}_{0}$, which goes from the unloading point to the strain axis. The $\mathrm{E}_{\mathrm{GS}}$ is required during the unloading/reloading regimes. Such modulus is represented by a straight line that starts in origin and intersects the cyclic path. The $\mathrm{E}_{\mathrm{GS}}$ can be expressed as Equation 22.

$$
E_{G S}=\sigma^{\prime} / \varepsilon^{\prime},
$$

where $\varepsilon^{\prime}$ is the current strain in the cycle, and $\sigma^{\prime}$ is the stress associated with $\varepsilon^{\prime}$ (Figure 3). The current stress $\sigma^{\prime}$ (Equation 23) is the unloading stress subtract from a stress variation $\Delta \sigma$ and must be written as a function of the known parameters $\mathrm{E}_{0}, \sigma_{u}, \varepsilon_{u}, \varepsilon^{\prime}$.

$$
\sigma^{\prime}=\sigma_{u}-\Delta \sigma .(23)
$$

The unloading strain $\left(\varepsilon_{u}\right)$ can be divided into elastic and permanent parcels, as indicated by Equation 24 .

$$
\varepsilon_{u}=\varepsilon^{e}+\varepsilon^{p} .
$$

As the cyclic path follows the undamaged elastic modulus, the stress variation is calculated with Equation 25.

$$
\Delta \sigma=E^{0}\left(\varepsilon_{u}-\varepsilon^{\prime}\right)
$$

Replacing $\Delta \sigma$ in Equation 23, the stress at any point of the cycle is given by Equation 26.

$$
\sigma^{\prime}=\sigma_{\mathrm{u}}-\mathrm{E}^{0} \varepsilon_{\mathrm{u}}+\mathrm{E}^{0} \varepsilon^{\prime}
$$


The linear elastic approach represents permanent strains, neglecting stiffness degradation. The $\mathrm{E}_{\mathrm{SG}}$ is used in the cycles, but the degradation remains fixed as the historical variable.

\subsubsection{Linear unloading/reloading based on the focal point}

In experiments, Lee et al. [22] and Lee and Willam [27] observed that the material unloading is directed to a pole. As presented in Figure 4, the cyclic path is a straight line defined by the unloading point $\left(\varepsilon_{\mathrm{u}}, \sigma_{\mathrm{u}}\right)$ and the focal point $\left(\varepsilon_{\mathrm{f}}, \sigma_{\mathrm{f}}\right)$.

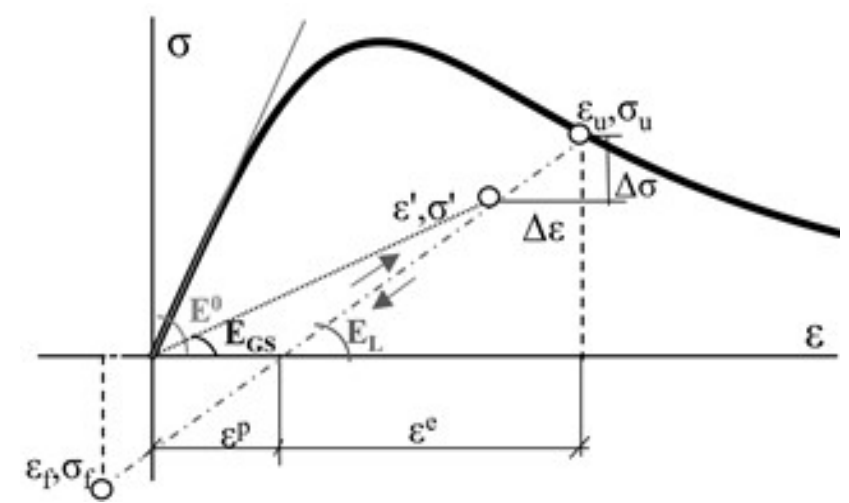

Figure 4. Linear unloading/reloading based on the focal point.

In the proposed method, the first step is the linear modulus $\left(E_{L}\right)$ calculus. This modulus represents the unloading/reloading straight slope given by Equation 27.

$$
\mathrm{E}_{\mathrm{L}}=\frac{\Delta \sigma}{\Delta \varepsilon}=\frac{\left(\sigma_{\mathrm{u}}-\sigma_{\mathrm{f}}\right)}{\left(\varepsilon_{\mathrm{u}}-\varepsilon_{\mathrm{f}}\right)}=\frac{\left(\sigma_{\mathrm{u}}-\sigma^{\prime}\right)}{\left(\varepsilon_{\mathrm{u}}-\varepsilon^{\prime}\right)}
$$

Then, Equation 27 is rewritten as Equation 28 to provide $\sigma^{\prime}$

$$
\sigma^{\prime}=\sigma_{\mathrm{u}}-\frac{\left(\sigma_{\mathrm{u}}-\sigma_{\mathrm{f}}\right)}{\left(\varepsilon_{\mathrm{u}}-\varepsilon_{\mathrm{f}}\right)}\left(\varepsilon_{\mathrm{u}}-\varepsilon^{\prime}\right)
$$

At last, the generalized secant modulus is obtained as Equation 29.

$$
E_{G S}=\frac{1}{\varepsilon^{\prime}}\left[\sigma_{u}-\frac{\left(\sigma_{u}-\sigma_{f}\right)}{\left(\varepsilon_{u}-\varepsilon_{f}\right)}\left(\varepsilon_{u}-\varepsilon^{\prime}\right)\right]
$$

The linear path based on a focal point improves cyclic material behavior representation since it can reproduce both stiffness degradation and permanent strain.

\subsubsection{Nonlinear unloading/reloading}

The previous focal point law has been extended to distinct unloading/reloading paths. Bono[29] adapted the original monotonic formulation of Popovics-Saez, introducing modifications in the origin and peak coordinates to make the cyclic analysis feasible. The Popovics-Saenz law proposed to describe the concrete monotonic compression behavior is calculated with Equation 30. 


$$
\sigma=\mathrm{f}_{\mathrm{i}} \frac{\mathrm{K}\left(\varepsilon / \varepsilon_{\mathrm{i}}\right)}{1+\mathrm{A}\left(\varepsilon / \varepsilon_{\mathrm{i}}\right)+\mathrm{B}\left(\varepsilon / \varepsilon_{\mathrm{i}}\right)^{2}+\mathrm{C}\left(\varepsilon / \varepsilon_{\mathrm{i}}\right)^{3}+\mathrm{D}\left(\varepsilon / \varepsilon_{\mathrm{i}}\right)^{\mathrm{R}}}, \text { with } \mathrm{i}=\mathrm{c} \text {, t. (30) }
$$

Where $\mathrm{K}=\mathrm{E}_{0}\left(\varepsilon_{\mathrm{i}} / \mathrm{f}_{\mathrm{i}}\right), \mathrm{R}=\mathrm{K} /(\mathrm{K}-1) ; \mathrm{f}_{\mathrm{i}}$ represents concrete strength, $\varepsilon$ is the current strain, and $\varepsilon_{\mathrm{i}}$ is the strain related to $\mathrm{f}_{\mathrm{i}}$. Physically, $\mathrm{R}$ is the reason between the elastic stress related to $\varepsilon_{\mathrm{i}}$ and the difference of this stress and $\mathrm{f}_{\mathrm{i}}$. A, B, C, $\mathrm{D}$ are variables dependent on the branch curve and the adjustment parameters $\beta_{\mathrm{ref}}$ and $\mathrm{k}_{\mathrm{ref}}$.

Kwon and Spacone [41] defined the focal point for compressive loading as the tensile strength. Under tension loading, an adequate monotonic curve should be adopted. The unloading/reloading paths, although, can be used without restrictions. In this case, the focal coordinate is the compressive strength. The $\mathrm{E}_{\mathrm{GS}}$ is calculated as shown in Equation 29.

\subsection{Cyclic monitoring}

The iterative incremental method requires a technique to control the load cycles imposed on the numerical model. Therefore, two monitoring methods have been developed to inform the start and end of the loops: the step count method and the load limit method.

The step count method (Figure 5) needs the step numbers where the unloading starts and ends. Despite its efficiency, the monotonic path must be previously known, and the load script depends on the increment size. On the contrary, the load limit method (Figure 6) defines the cycles from the load values at the beginning of unloading and reloading. Tolerance is required since the equilibrium path points may not coincide with the specified limits. The load limit method is practical if the cycles loci are known from experimental data.

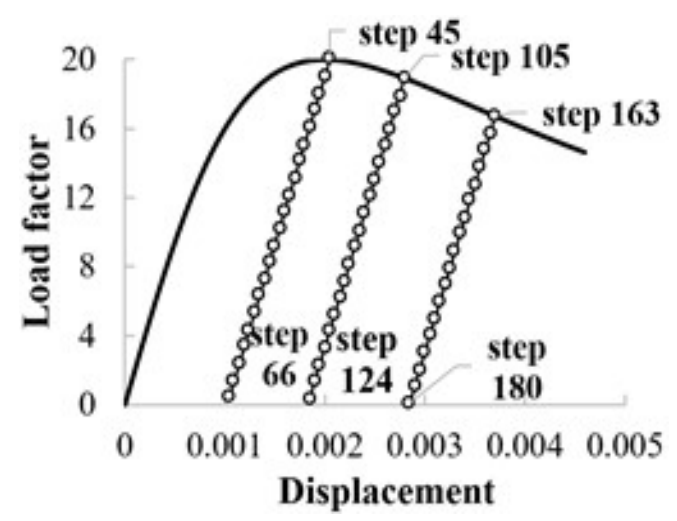

Figure 5. Cycle control - steps count.

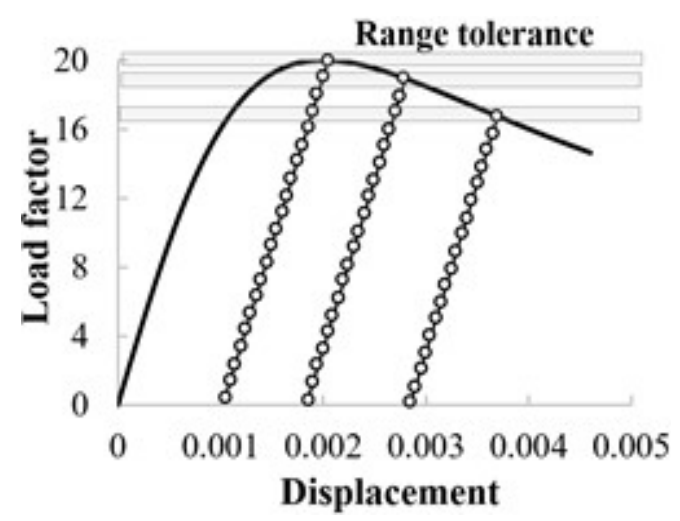

Figure 6. Cycle control - load limit. 
Both monitoring methods operate at the displacement increment. To perform the unloading, once the critical point is identified into the Newton-Raphson algorithm, such increment is multiplied by -1.0. The reloading occurs with a second sign inversion. At this moment, the loading is resumed, driving back to the monotonic curve. For material points under the elastic regime, the unloading/reloading path agrees with the monotonic curve. This strategy is applied to the direct displacement control method, and there is no cycle number limit. The algorithm presented in Figure 7 summarizes the cyclic monitoring procedure.

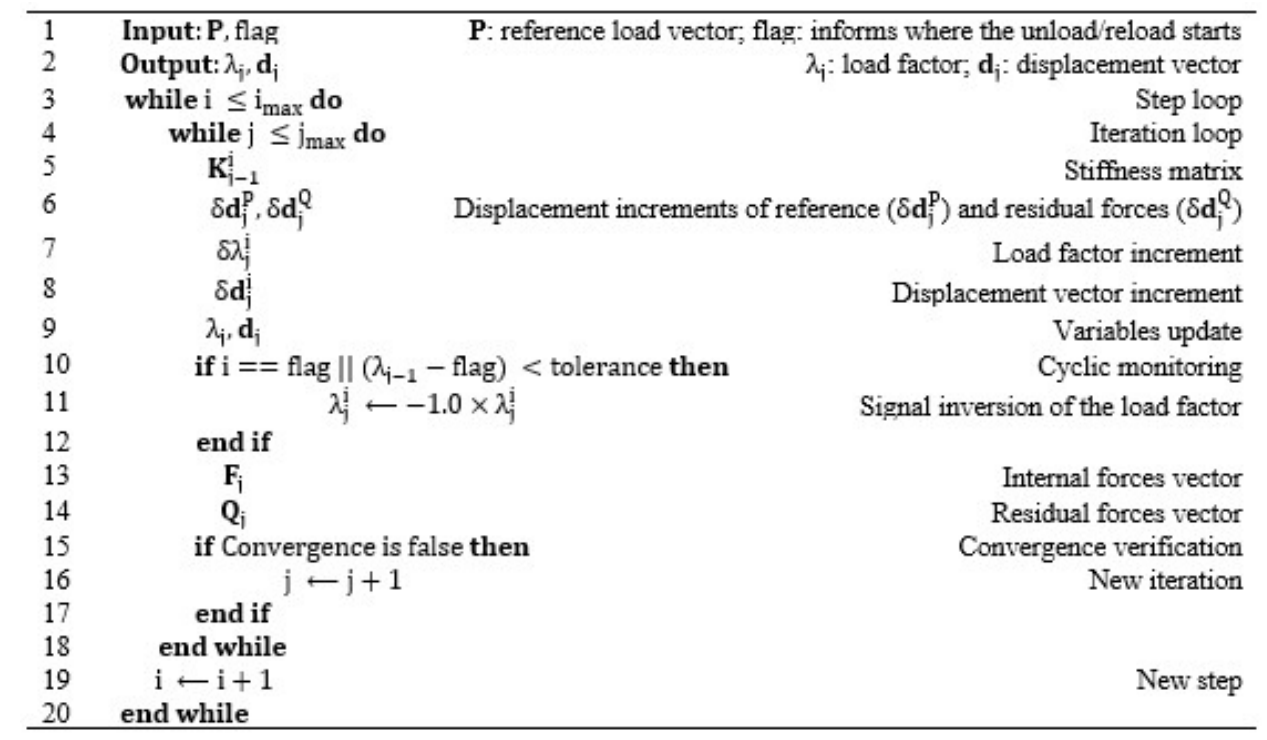

Figure 7. Standard Newton-Raphson algorithm, including the cyclic monitoring.

\section{NUMERICAL SIMULATIONS}

Numerical analyses have been performed in the INSANE (INteractive Structural ANalysis Environment), an opensource code developed at the Department of Structural Engineering of the Federal University of Minas Gerais, to evaluate the response of the proposed model. The first two examples consist of direct tension and direct compression, respectively. The proposed method has been validated by comparing the obtained results with experimental curves from the literature. The third example is a three-point bending test of a plain concrete beam. Finally, a reinforced concrete (RC) beam is submitted to a cyclic distributed load.

\subsection{Direct tension}

Golaparatnam and Sha [42] performed a series of experiments in plain concrete samples under cyclic tension with prismatic geometry $(76 \times 19 \times 305 \mathrm{~mm})$. The concrete properties are tensile strength $\mathrm{f}_{\mathrm{t}}=3.53 \mathrm{MPa}$, tensile strain limit in the elastic regime $\varepsilon_{t}=1.18 \times 10^{-4}$, and fracture energy $\mathrm{G}_{\mathrm{f}}=0.0564 \mathrm{~N} / \mathrm{mm}$.

Initially, a refinement test was performed in a monotonic analysis to define the mesh sensitivity. In the simulation, five meshes were analyzed, with 1, 4, 16, 60, and 320 elements. Since no evidence of localization effects was verified, the mesh with 60 four-node quadrilateral finite elements was adopted, considering an intermediate level of refinement.

The loading process assumed a reference load $\mathrm{q}=19 \mathrm{~N} / \mathrm{mm}$, displacement increment of $5.0 \times 10^{-7} \mathrm{~m}$, and tolerance for the convergence in displacement of $1.0 \times 10^{-4}$. The cycles were introduced by the load limit monitoring method. Figure 8 illustrates the geometry configuration, the boundary conditions, the mesh, and the controlled degree of freedom.

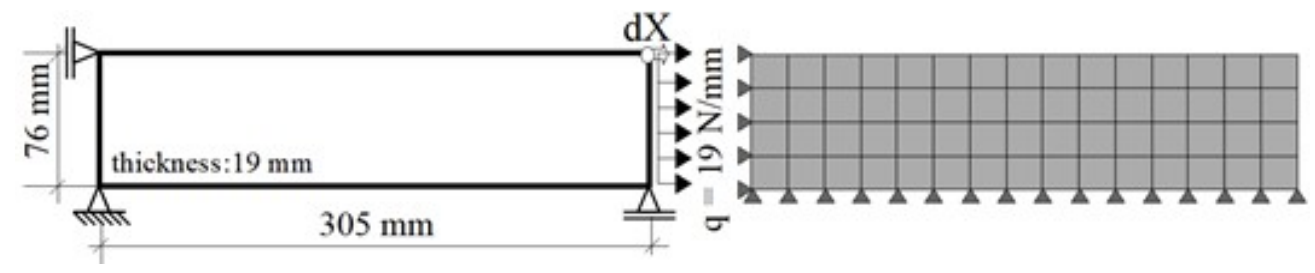

Figure 8. Direct tension simulation - geometry and mesh. 
The material law by Boone et al. [25] and Boone and Ingraffea [26], and the Carreira and Chu [23], [24] were adopted to tension and compression, respectively. Besides the experimental parameters [42], other material properties were considered: Poisson ratio of 0.18 [43]; compressive strength of 40.4 MPa estimate from the relation [44], indicated in Equation 31.

$$
\mathrm{f}_{t}=0.3\left(f_{c}\right)^{2 / 3}
$$

and the elastic limit of the compressive strain $\varepsilon_{\mathrm{c}}=0.002$, from the NBR 6118 [45].

The characteristic length (h) is a parameter associated with the fracture process zone. Such value is usually related to the maximum aggregate size [46]. In the absence of information, (h) can be obtained from the region dimension used to measure the experimental strains. Here, it was considered $\mathrm{h}=166 \mathrm{~mm}$. The shear retention factor was admitted as $\beta \mathrm{r}=0,05$, a traditional value for plain concrete [47]. The maximum secant moduli degradation was limited to $92 \%$. This number came from the monotonic path fitting to the experimental curve. For the linear unloading/reloading approach, the focal point is the concrete compressive strength. For the nonlinear cyclic strategy, the focal point of the stretch direction $\left(\varepsilon_{f 1}, \sigma_{f 1}\right)$ is also the compressive strength, while the compressed direction focus $\left(\varepsilon_{\mathrm{f} 2}, \sigma_{\mathrm{f} 2}\right)$ is the tensile strength [41]. An extra simulation was performed for the nonlinear formulation considering the origin as the focus to both directions. Parametrization of the law by Popovic-Saez was done to fit Carreira and Chu [23], [24] monotonic curve, providing $\beta_{\text {ref }}=1.8$ and $\mathrm{k}_{\mathrm{ref}}=0.85$. Table 1 resumes the material parameters.

Table 1. Material parameters: direct tension.

\begin{tabular}{|c|c|c|c|c|c|c|c|}
\hline \multirow{2}{*}{\multicolumn{4}{|c|}{$\begin{array}{l}\text { Compressive }[23],[24] \text { and } \\
\text { tension }[25],[26] \text { law }\end{array}$}} & \multicolumn{4}{|c|}{ Linear focus law [22], [27] } \\
\hline & & & & $\varepsilon_{\mathrm{f}}$ & -0.002 & $\sigma_{\mathrm{f}}$ & $-40.4 \mathrm{MPa}$ \\
\hline \multirow{2}{*}{$\begin{array}{l}\mathrm{f}_{\mathrm{c}} \\
\varepsilon_{\mathrm{c}}\end{array}$} & $40.4 \mathrm{MPa}$ & $\mathrm{f}_{\mathrm{t}}$ & $3.53 \mathrm{MPa}$ & \multicolumn{4}{|c|}{ Popovics-Saenz law [28]-[31] } \\
\hline & 0.002 & $\mathrm{E}$ & $29,915 \mathrm{MPa}$ & $\beta_{\text {ref }}$ & 1.8 & $\mathrm{k}_{\mathrm{ref}}$ & 0.85 \\
\hline$v$ & 0.18 & $\mathrm{G}_{\mathrm{f}}$ & $0.0564 \mathrm{~N} / \mathrm{mm}$ & $\varepsilon_{\mathrm{f} 1}$ & -0.002 & $\sigma_{\mathrm{f} 1}$ & $-40.4 \mathrm{MPa}$ \\
\hline $\mathrm{h}$ & $166 \mathrm{~mm}$ & $\beta_{\mathrm{r}}$ & 0.05 & $\varepsilon_{\mathrm{f} 2}$ & 0.000118 & $\sigma_{\mathrm{f} 2}$ & $3.53 \mathrm{MPa}$ \\
\hline
\end{tabular}

The numerical stress-strain relations are shown in Figure 9, contrasting with the experimental curve from Gopalaratnam e Shah [42].

Since the secant strategy is based on an elastic degradation model, all the cycles are directed to the origin, and its priority is stiffness deterioration reproduction. The agreement between the simulated cycle initiation and the unloading points from the experimental curve was used to achieve representative results. The permanent strain is represented in the elastic approach. Thus, the reloading points were prescribed to be as close as possible to the experimental residual strains. The stiffness degradation, however, is neglected.

The cyclic laws based on the focal point embrace both phenomena: stiffness degradation and permanent strain representation. The cyclic path remained linear for the simulation using the nonlinear law where the focus is concrete compressive strength, presenting a similar result to the elastic strategy. This fact is related to the distance between the unloading points and the focus. Although, this approach showed its potential to represent hysteresis with distinct unloading/reloading paths when the focal point was set in origin.

As observed in the comparison between experimental and numerical curves, the last cycles have presented a less accurate representation. This result is related to the high level of degradation [1], [12], [13]. Therefore, a possible solution includes a variable focal point, depending on the current material degradation.

The last analysis evaluated the potential of a variable focus. The focal point coordinates of each cycle coincide with the null stress and the plastic strain related to that loop in the experimental curve. Figure 9 shows that the focal point strongly affects the configuration of the cycles, permitting a better adjustment of the numerical response. 
Despite the restrictions of the adopted stress-strain laws, described as a linear path in most cases, they have represented concrete cyclic behavior satisfactorily. The approaches based on the focal point are more efficient in reproducing experimental results since they couple stiffness degradation and residual strain. However, analyzing such phenomena individually and disregarding the configuration of the cycles, the elastic strategy has been the most adequate approach to describe permanent strain. The secant representation has shown numerical robustness using the actual secant modulus. Based on these issues, the cyclic law selection must be guided by the drawbacks and the advantages of each law.
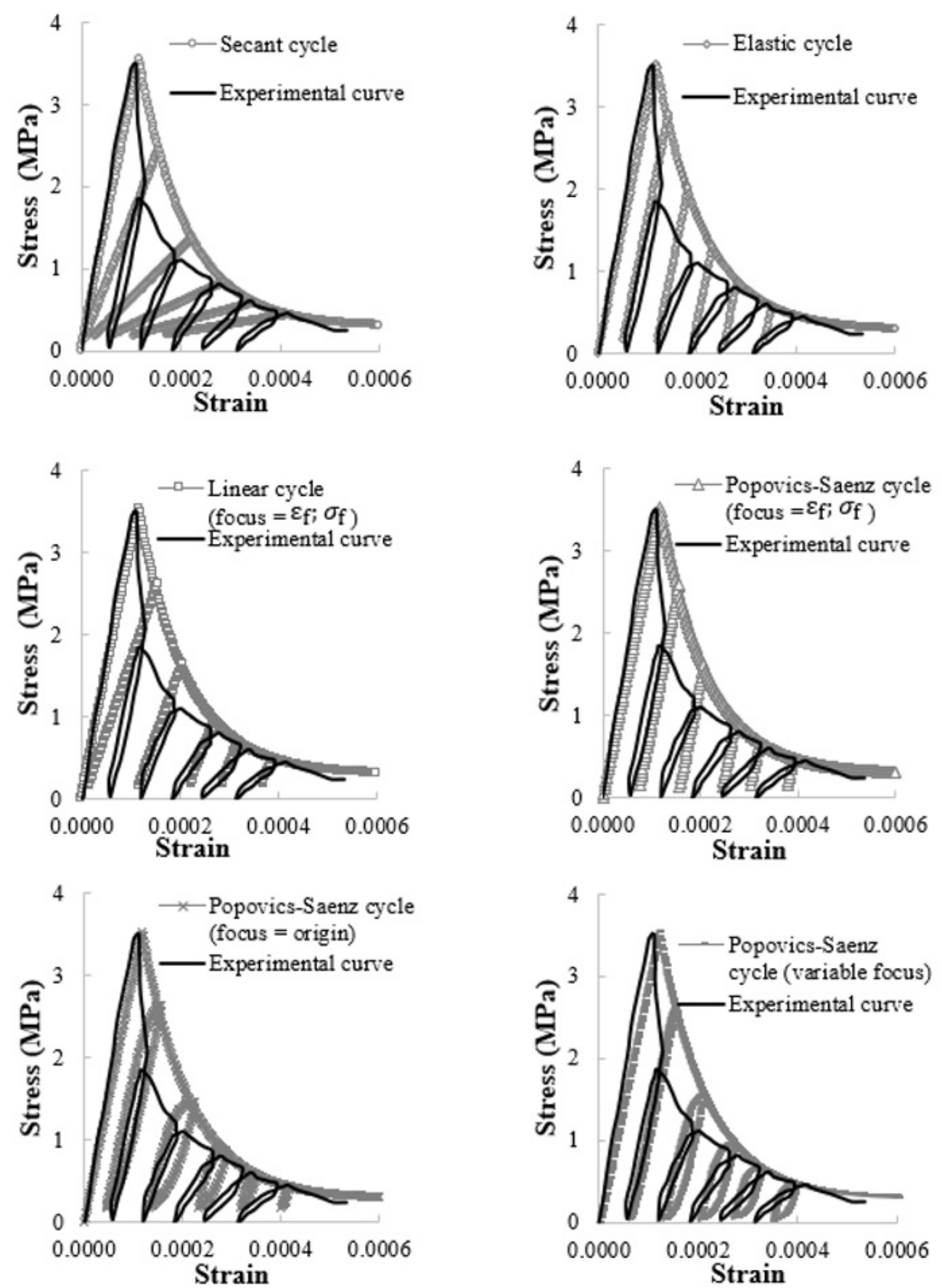

Figure 9. Direct tension simulations: different strategies to represent the load cycles. 


\subsection{Direct compression}

Based on the experimental tests by Karsan and Jirsa [11], a cyclic compression was modeled. A refinement test was performed to define the mesh of $4 \times 4$ four-nodes quadrilateral (Figure 10). A load of $q=19 \mathrm{~N} / \mathrm{mm}$, a displacement increment of $-5.0 \times 10^{-7} \mathrm{~m}$, and a tolerance convergence in load and displacement of $1.0 \times 10^{-4}$ drove the loading process. The cycles were controlled by the load limit method.

The material parameters from the experimental test are: Poisson ratio $v=0.18$; elastic modulus $\mathrm{E}=31,700 \mathrm{MPa}$; fracture energy $\mathrm{G}_{\mathrm{f}}=0.04 \mathrm{~N} / \mathrm{mm}$; concrete compressive strength $\mathrm{f}_{\mathrm{c}}=27.6 \mathrm{MPa}$; and characteristic length $\mathrm{h}=82.6 \mathrm{~mm}$. The other parameters were estimated as: concrete tensile strength $\mathrm{f}_{\mathrm{t}}=2.76 \mathrm{MPa}$ (Equation 31 ); strain in the compressive elastic limit $\varepsilon_{\mathrm{c}}=0.0016$ [45]; shear retention factor $\beta_{\mathrm{r}}=0,05$ [47].

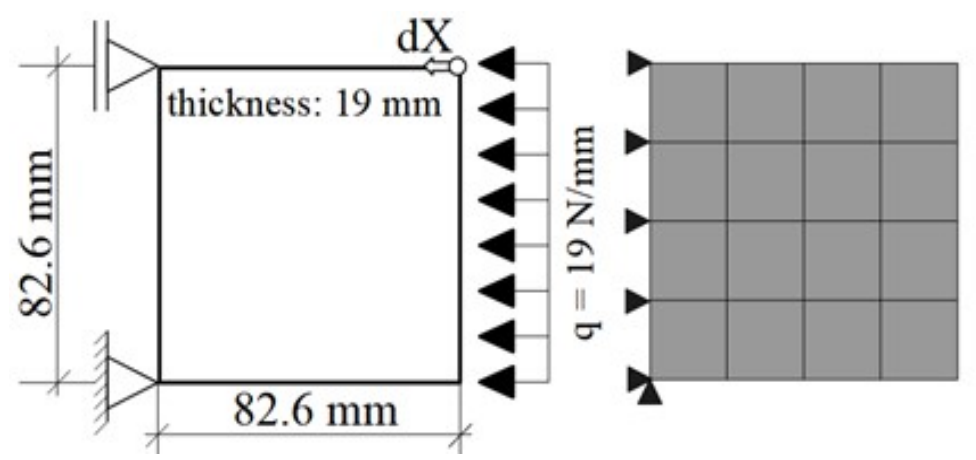

Figure 10. Direct compression simulation - geometry and mesh.

The concrete tensile strength parameter $\left(\mathrm{f}_{\mathrm{t}}\right)$ is necessary to determine the focus of the linear law based on the focal point. Such focus was also adopted to the compressive direction for the law by Popovics-Saenz [28]-[31]. The concrete compressive strength, otherwise, was defined as the focal point for the tension direction. The parameters of the law proposed by Popovics-Saenz's were established to fit Carreira and Chu [23], [24] monotonic curve. The secant moduli maximum degradation was $90 \%$. Table 2 summarizes all the parameters required by the stress-strain laws.

Table 2. Material parameters: direct compression.

\begin{tabular}{|c|c|c|c|c|c|c|c|}
\hline \multirow{2}{*}{\multicolumn{4}{|c|}{$\begin{array}{l}\text { Compressive }[23],[24] \text { and } \\
\text { tension }[25],[26] \text { law }\end{array}$}} & \multicolumn{4}{|c|}{ Linear focus law [22], [27] } \\
\hline & & & & $\varepsilon_{\mathrm{f}}$ & 0,000087 & $\sigma_{f}$ & $2.76 \mathrm{MPa}$ \\
\hline \multirow{2}{*}{$\begin{array}{l}f_{c} \\
\varepsilon_{c}\end{array}$} & $27.6 \mathrm{MPa}$ & $\mathrm{f}_{\mathrm{t}}$ & $2.76 \mathrm{MPa}$ & \multicolumn{4}{|c|}{ Popovics-Saenz law [28]-[31] } \\
\hline & 0.0016 & $\mathrm{E}$ & $31,700 \mathrm{MPa}$ & $\beta_{\text {ref }}$ & 1.7 & $\mathrm{k}_{\mathrm{ref}}$ & 0.85 \\
\hline$v$ & 0.18 & $\mathrm{G}_{\mathrm{f}}$ & $0.04 \mathrm{~N} / \mathrm{mm}$ & $\varepsilon \mathrm{f} 1$ & 0.000087 & $\sigma_{\mathrm{fl} 1}$ & $2.76 \mathrm{MPa}$ \\
\hline $\mathrm{h}$ & $82.6 \mathrm{~mm}$ & $\beta_{\mathrm{r}}$ & 0.05 & $\varepsilon_{\mathrm{f} 2}$ & -0.0016 & $\sigma_{\mathrm{f} 2}$ & $-27.6 \mathrm{MPa}$ \\
\hline
\end{tabular}

The responses (Figure 11) highlight the conclusions obtained in the compression simulations.

The secant law is restricted to degradation stiffness representation, while the elastic law can only reproduce residual strains. The results from the linear law based on the focal point show both phenomena, although the cycles remain simplified by a straight. Nevertheless, the cycles reproduced by the nonlinear law, considering the focus either in the concrete tensile strength or origin, showed the capacity to describe the experimental cyclic paths. Although, a discrepancy between the hysteresis loops from the test and the numerical simulations is noted. Such differences are related to the parametrization difficulty of the cyclic models. Since monotonic tests define the variables of the stressstrain laws, a relation among these parameters and the unloading/reloading regimes is unknown. The only variable that may change the cyclic configuration is the focal point. 
In general, Popovics-Saenz [28]-[31] law with the focal point on the concrete tensile strength is a valid representation of the experimental curve. The proposed model could present a more precise reproduction of the cycles with an accurate definition of the focal point. Like the tension analysis, a numerical simulation was performed considering a variable focal point. Each cycle was directed to the intersection point between the empirical loop and the strain axis. The shapes of the load cycles fit the experimental curve better, although it is still necessary to determine a variable capable of controlling the hysteresis amplitude.
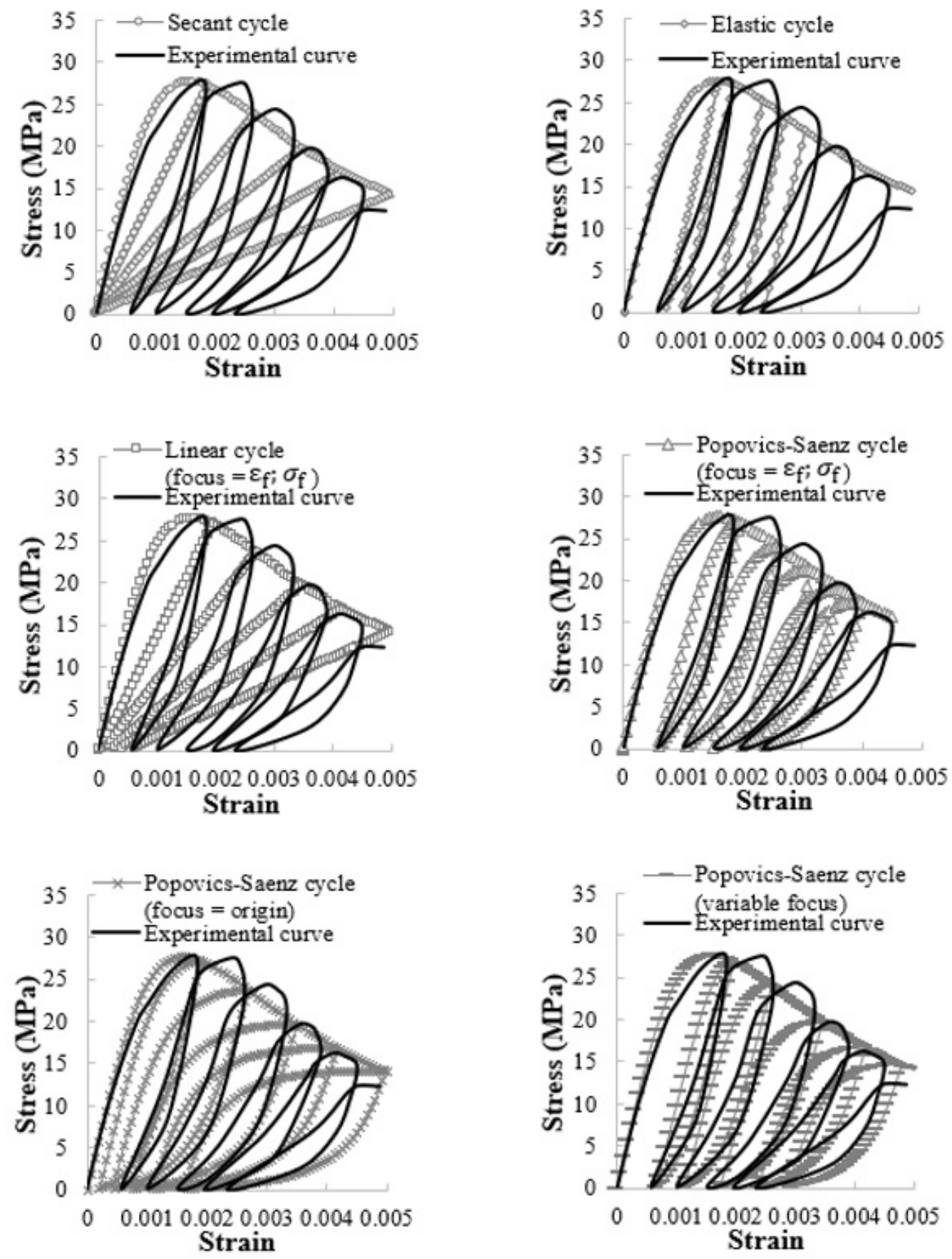

Figure 11. Direct compression simulations: different strategies to represent the load cycles. 


\subsection{Three-point bending test}

This simulation modeled a three-point bending to evaluate the model response in more general load conditions. The geometry of the beam is illustrated in Figure 12, as in the reference work of Hordijk [48]. The node and the direction controlled are also highlighted. Because of the geometric symmetry, only half of the beam was modeled. The finite element model consists of 180 four-nodes quadrilateral elements in a plane stress state.

The loading process has assumed a unit load $\mathrm{P}$, a displacement increment of $-2.0 \times 10^{-3} \mathrm{~m}$, and a convergence in displacement of $1.0 \times 10^{-4}$. The monitoring method by load limit was selected. The plain concrete is characterized by the parameters in Table 3, as given by [48].
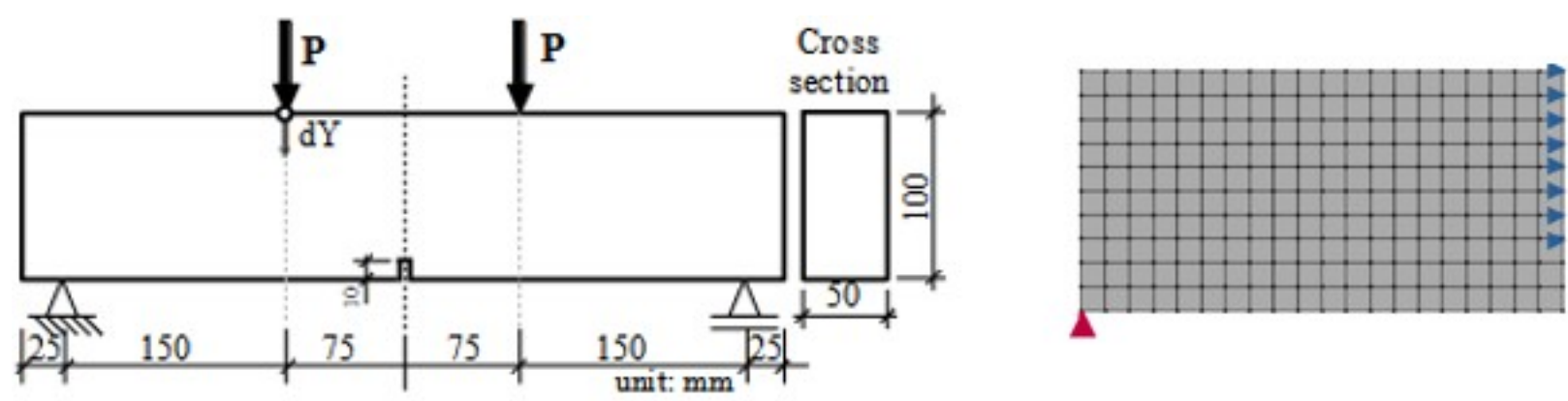

Figure 12. Three-point bending test: geometry and mesh.

The reference curve is the experimental test of Hordijk [48]. Variable focal points were adopted in the linear law based on the experimental reload points. The origin was the focus of the Popovics-Saenz law. The results are shown in Figure 13.

Table 3. Material parameters: three-point bending test.

\begin{tabular}{|c|c|c|c|c|c|c|c|}
\hline \multicolumn{4}{|c|}{ Compressive $[23],[24]$ and tension $[25],[26]$ law } & \multicolumn{4}{|c|}{ Popovics-Saenz law [28]-[31] } \\
\hline$f_{c}$ & $59.5 \mathrm{MPa}$ & $\mathrm{f}_{\mathrm{t}}$ & $3.75 \mathrm{MPa}$ & $\beta_{\text {ref }}$ & 1.8 & $\mathrm{k}_{\mathrm{ref}}$ & 0.85 \\
\hline$\varepsilon_{\mathrm{c}}$ & 0.002 & $\mathrm{E}$ & $40485 \mathrm{MPa}$ & $\varepsilon_{\mathrm{f}}$ & 0.0 & $\sigma_{\mathrm{f}}$ & 0.0 \\
\hline$v$ & 0.2 & $\mathrm{G}_{\mathrm{f}}$ & $0.115 \mathrm{MN} / \mathrm{m}$ & & & & \\
\hline $\mathrm{h}$ & $15 \mathrm{~m}$ & $\beta_{\mathrm{r}}$ & 0.0001 & & & & \\
\hline
\end{tabular}

The secant strategy showed robustness in cyclic reproduction, while the other approaches exhibited instabilities. The cyclic elastic approach reproduced only the first cycle, and not even the step size reduction allowed it to conclude the simulation. The laws based on the focal point reached a more advanced strain state in the analysis, but they failed after the third cycle when numerical instabilities interrupted the simulation by not meeting the convergence.

These instabilities must be related to the $\mathrm{E}_{\mathrm{GS}}$ in complex load states since the material points can present load sign inversion, even when an inversion is not observed in the structural behavior. A quadrant mapping of the stress-strain space is required to consider negative and positive quantities, improving the proposed model to embrace general load cases. The focal point is another subject that deserves attention in future works because of the dependency of the load loops on this variable. Nevertheless, the results show that all cycle hypotheses agree with the behavior observed in direct tension and direct compression from the literature. 

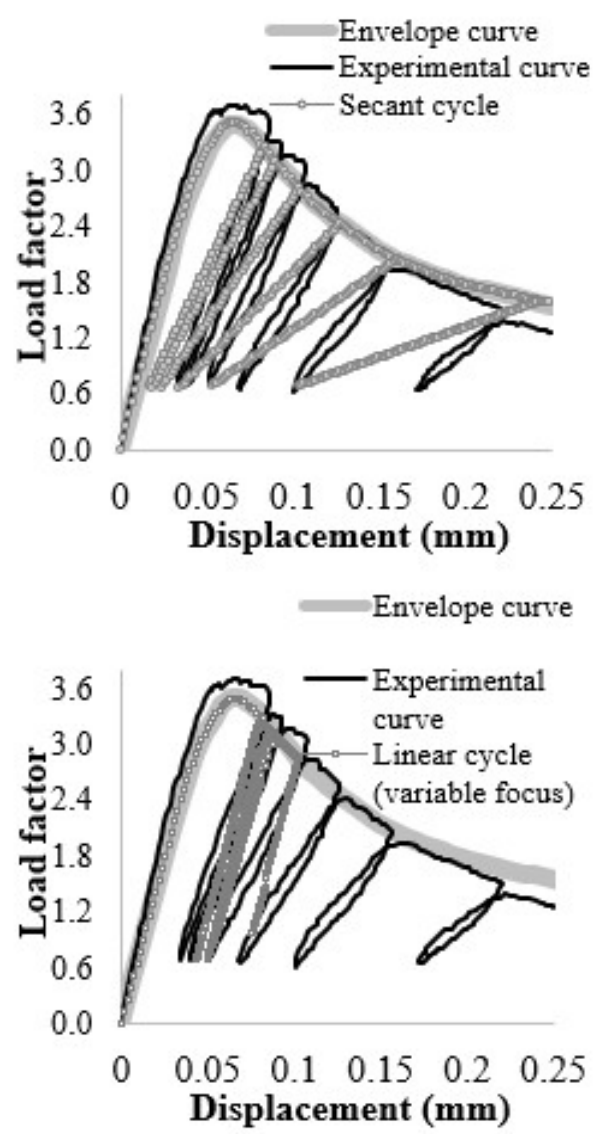
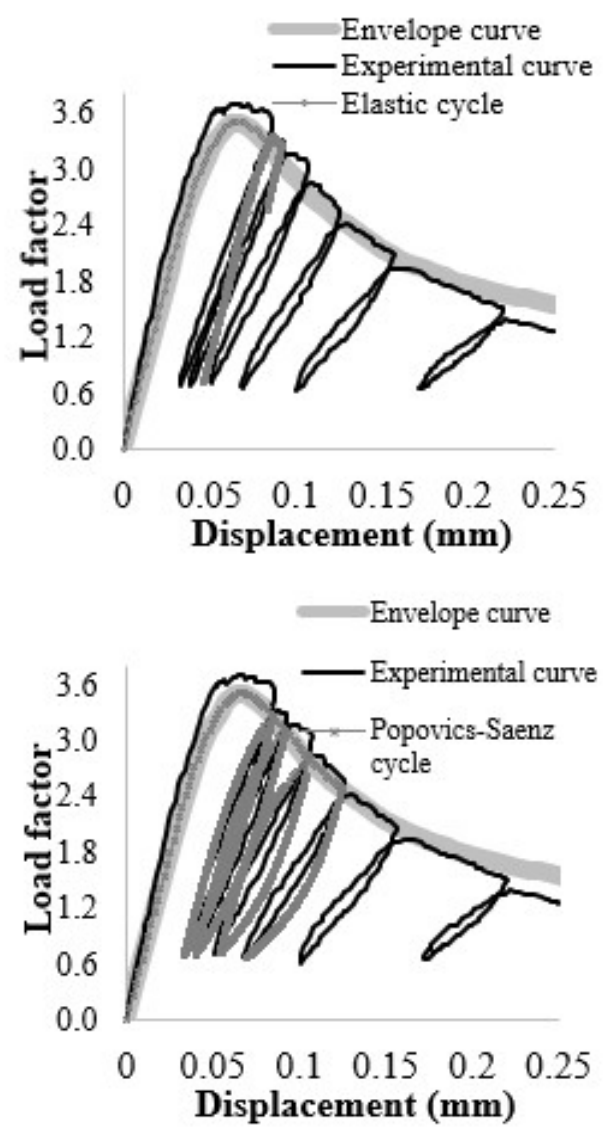

Figure 13. Three-point bending test: different strategies to represent the load cycles

\subsection{Reinforced concrete beam subjected to uniform loading}

A reinforced concrete (RC) beam subjected to a uniformly distributed load was modeled. Since RC is a material compound of concrete and steel, a combination of cyclic behaviors was adopted. The secant cycles were selected to represent the concrete elastic degradation, while the elastic cycles were adopted for steel to reproduce plastic strains during the yielding.

The structure dimensions were based on typical beams from projects (Figure 14). The mesh has 420 four-node quadrilateral concrete elements, and two-node bar elements represent the reinforcing steel. The material parameters are summarized in Table 4 . The steel behavior was considered elastic-perfectly plastic with a perfect bond between steel and concrete.

The vertical displacement in the midspan of the beam was controlled with an increment of $-1.0 \times 10^{-4} \mathrm{~m}$, convergence tolerance in displacement of $1.0 \times 10^{-5}$, and a distributed loading of $\mathrm{q}=0.33 \mathrm{MN} / \mathrm{m}$. The monitoring method by step count was selected, introducing three arbitrary cycles in the equilibrium path after the steel yielding to reproduce an intense unloading/reloading regime. The secant cycles were performed considering two different compressive laws for concrete: Carreira and Chu [23], [24], and Popovics-Saenz [28]-[31].

The structural response is shown in Figure 15, and the critical degradation stages are highlighted along the equilibrium path. As a reference, a curve is presented based on the reinforced concrete stages representing the elastic behavior of the materials, the concrete cracking phase, and the yield of the reinforcement. The microcrack nucleation (1) is observed when the graphic becomes nonlinear, and concrete starts to damage. Then, the microcracks grow (2) until a critical point in which the nonlinearities are significant. Thus, the microcracks coalescence culminate in macrocracks (3). In the last stage, the macrocracks propagate in concrete, and the steel reaches the plastification (4). 


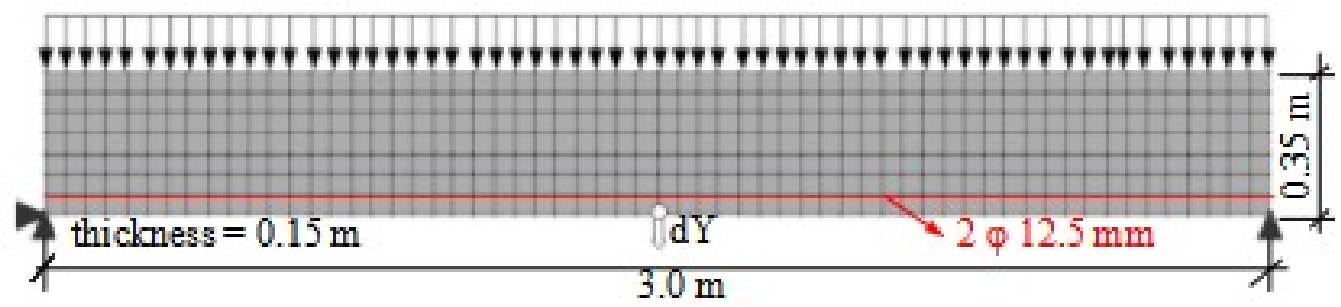

Figure 14. Reinforced concrete beam - geometry and mesh.

Table 4. Material parameters: concrete and steel.

\begin{tabular}{ccccccccccc}
\hline \multicolumn{4}{c}{ Concrete: compressive [23], [24] and tension [25], [26] law } & \multicolumn{2}{c}{ Steel: Von Mises criteria } \\
\hline $\mathrm{f}_{\mathrm{c}}$ & $20.0 \mathrm{MPa}$ & $\mathrm{f}_{\mathrm{t}}$ & $2.0 \mathrm{MPa}$ & $v$ & 0.2 & $\mathrm{G}_{\mathrm{f}}$ & $3.0 \times 10^{-5} \mathrm{MN} / \mathrm{m}$ & $\mathrm{E}$ & $210,000 \mathrm{MPa}$ \\
\hline$\varepsilon_{\mathrm{c}}$ & 0.002 & $\varepsilon_{\mathrm{t}}$ & 0.00008 & $\beta_{\mathrm{ref}}$ & 1.8 & $\mathrm{k}_{\mathrm{ref}}$ & 0.85 & $v$ & 0.2 \\
\hline $\mathrm{E}$ & $25,000 \mathrm{MPa}$ & $\beta_{\mathrm{r}}$ & 0.05 & $\mathrm{~h}$ & $0.06 \mathrm{~m}$ & focus & origin & $\mathrm{f}_{\mathrm{y}}$ & $500 \mathrm{MPa}$ \\
\hline
\end{tabular}

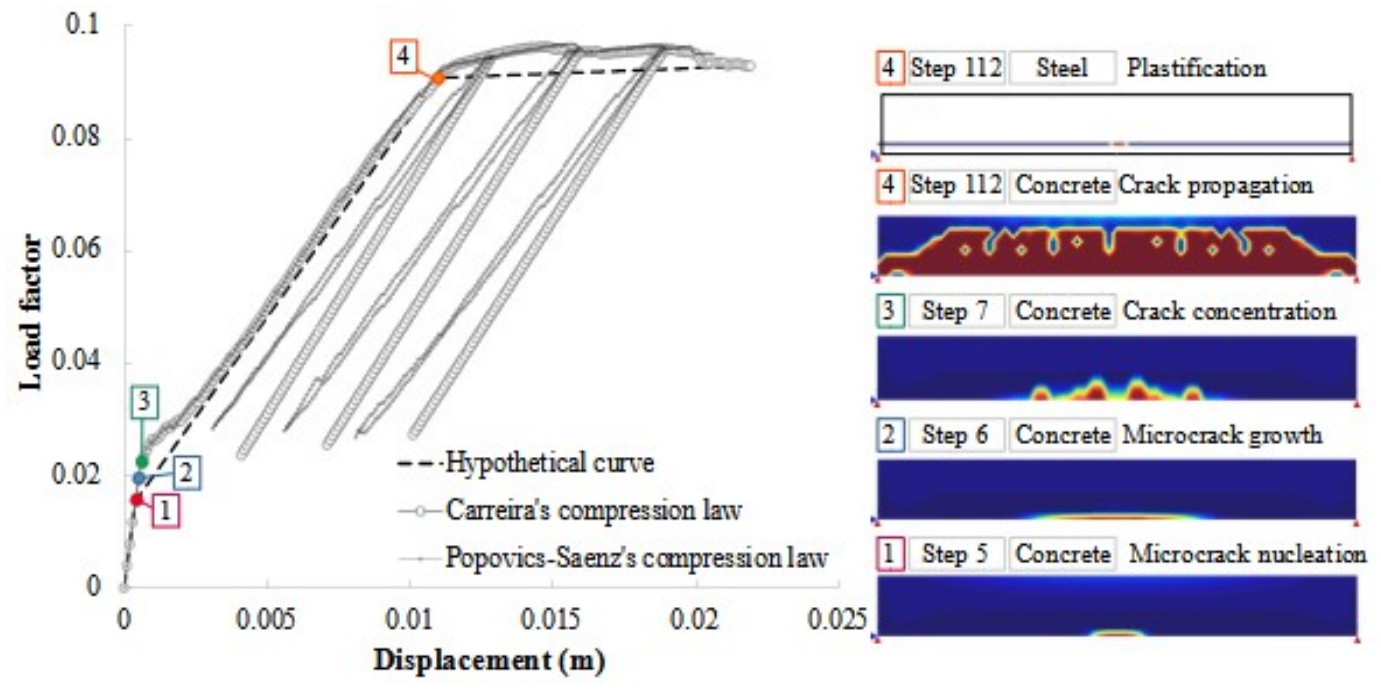

Figure 15. Reinforced concrete beam cyclic simulations.

The results from the simulation with the law by Carreira and Chu [23], [24] show an elastic cyclic behavior, while the simulation using the material description by Popovics-Saenz has a response between the elastic and the secant approaches. The selected concrete monotonic curve changed the cyclic configuration, but the steel conducted the unloading/reloading process in both analyses during the yielding stage.

\section{CONCLUSIONS}

A smeared crack model based on elastic degradation under cyclic loadings has been presented, aiming at a generalized secant modulus numerical approach. Four stress-strain laws with unloading/reloading descriptions have been adopted. The proposed method was validated by comparing numerical results of concrete under cyclic loading in compression and tension with experimental curves from the literature, resulting in good agreement. Three-point bending tests have been simulated for plain and reinforced concrete to evaluate the viability of applying this model to general cases. In this context, the main conclusions are: 
i. The numerical analyses have shown that the developed method based on the generalized secant modulus fulfill the proposed aim, simulating load cycles with distinct characteristics;

ii. The examples validated by experimental curves prove the effectiveness of the strategies developed for concrete structures subjected to cyclic tension and cyclic compression;

iii. The implementation of the cyclic stress-strain laws has been successfully realized, and the variety of material laws allows versatility in the hysteresis representation;

iv. The approaches based on the focal point have the advantage of reproducing both stiffness degradation and residual strains;

v. The bending analysis has evaluated the present formulation application to simulate structures under conventional loads. Since numerical instabilities have been observed, an investigation must be carried to improve the proposed model to embrace general loads;

vi. The proposed methodology seems capable of simulating reinforced concrete structures, coupling the developed cyclic model for concrete with a plasticity model for steel.

\section{ACKNOWLEDGEMENTS}

The authors are grateful for the financial support of CNPq (in Portuguese "Conselho Nacional de Desenvolvimento Científico e Tecnológico") - Grant n 307985/2020-2.

\section{CITATIONS}

[1] D. Z. Yankelevsky and H. W. Reinhardt, "Uniaxial behavior of concrete in cyclic tension," J. Struct. Eng., vol. 115, no. 1, pp. 166182, Jan. 1989, http://dx.doi.org/10.1061/(ASCE)0733-9445(1989)115:1(166).

[2] P. Zhang, Q. Ren, and D. Lei, "Hysteretic model for concrete under cyclic tension and cyclic tension-compression reversals," Eng. Struct., vol. 163, pp. 388-395, May. 2018, http://dx.doi.org/10.1016/j.engstruct.2018.02.051.

[3] Y. R. Rashid, "Ultimate strength analysis of prestressed concrete pressure vessels," Nucl. Eng. Des., vol. 7, no. 4, pp. 334-344, Apr. 1968, http://dx.doi.org/10.1016/0029-5493(68)90066-6.

[4] Z. P. Bažant, "Instability, ductility and size effect in strain-softening concrete," ASCE J. Eng. Mech. Div., vol. 102, no. 2, pp. 331344, Apr. 1976, http://dx.doi.org/10.1061/JMCEA3.0002111.

[5] J. G. Rots, P. Nauta, G. M. Kusters, and J. Blaauewendrra, "Smeared crack approach and fracture localization in concrete," Heron, vol. 30, no. 1, pp. 1-48, Jan. 1985.

[6] J. G. Rots and R. Borst, "Analysis of mixed-mode fracture in concrete," J. Eng. Mech., vol. 113, no. 11, pp. 1739-1758, Nov 1987., http://dx.doi.org/10.1061/(ASCE)0733-9399(1987)113:11(1739).

[7] J. Mazars and G. Pijaudier-Cabot, "Continuum damage theory - application to concrete," J. Eng. Mech., vol. 115, no. 2, pp. 345-365, Feb. 1989, http://dx.doi.org/10.1061/(ASCE)0733-9399(1989)115:2(345).

[8] J. Lemaitre, A course on damage mechanics, 1st ed. New York, US: Springer, 1992.

[9] J. H. P. Vree, W. A. M. Brekelmans, M. A. J. Van Gils, "Comparison of nonlocal approaches in continuum damage mechanics," Comput. Struc., vol. 55, no. 4, pp. 581-588, May. 1995, http://dx.doi.org/10.1016/0045-7949(94)00501-S.

[10] B. P. Sinha, K. H. Gerstle, and L. G. Tulin, "Stress-strain relations for concrete under cyclic loading," ACI Struct. J., vol. 61, no. 2, pp. 195-212, Feb. 1964, http://dx.doi.org/10.14359/7775.

[11] I. D. Karsan and S. O. Jirsa, "Behavior of concrete under compressive loadings," J. Struct. Div., vol. 95, no. 12, pp. 2543-2563, Dec. 1969, http://dx.doi.org/10.1061/JSDEAG.0002424.

[12] D. Z. Yankelevsky and H. W. Reinhardt, "Model for cyclic compressive behavior of concrete," J. Struct. Eng., vol. 113, no. 2, pp. 228-240, Feb. 1987, http://dx.doi.org/10.1061/(ASCE)0733-9445(1987)113:2(228).

[13] D. Z. Yankelevsky and H. W. Reinhardt "Focal point model for uniaxial cyclic behavior of concrete," in IABSE Colloquium (Delft), 1987, pp. 99-106. http://doi.org/10.5169/seals-41920.

[14] J. F. Sima, P. Roca, and C. Molins, "Cyclic constitutive model of concrete," Eng. Struct. J., vol. 30, no. 3, pp. 695-706, Mar. 2008, http://dx.doi.org/10.1016/j.engstruct.2007.05.005.

[15] M. Breccolotti, M. Bonfible, A. D’Alessandro, and A. Materazzi, "Constitutive modeling of plain concrete subjected to cyclic uniaxial compressive loading," Constr. Build. Mater., vol. 94, pp. 172-180, Jul. 2015, http://dx.doi.org/10.1016/j.conbuildmat.2015.06.067.

[16] D.-C. Feng, Z. Wang, X.-Y. Cao, and G. Wu, "Damage mechanics-based modeling approaches for cyclic analysis of precast concrete structures," Int. J. Damage Mech., vol. 29, no. 6, pp. 965-987, Jan. 2020, http://dx.doi.org/10.1177/1056789519900783.

[17] G. M. S. Alva, R. M. F. Canha, J. Oliveira Fo., and A. L. H. C. El Debs, "Numerical model for analysis of reinforced concrete beams under repeated cyclic loads," Sci. Eng. J., vol. 22, no. 2, pp. 105-114, Dec. 2013, http://dx.doi.org/10.14393/19834071.2013.23805. 
[18] X. Chen, L. Xu, and J. Bu, "Experimental study and constitutive model on complete stress-strain relation of plain concrete in uniaxial cyclic tension," KSCE J. Civ. Eng., vol. 21, no. 5, pp. 1829-1835, Sep. 2017, http://dx.doi.org/10.1007/s12205-016-0802-0.

[19] M. Moharrami and I. Koutromanos, "Triaxial constitutive model for concrete under cyclic loading," J. Struct. Eng., vol. 142, no. 7, pp. 1-15, Feb. 2016, https://doi.org/10.1061/(ASCE)ST.1943-541X.0001491.

[20] C. Mourlas, M. Papadrakakis, and G. Markou, "A computationally efficient model for the cyclic behavior of reinforced concrete structural members," Eng. Struct., vol. 141, pp. 97-125, Mar. 2017, http://dx.doi.org/10.1016/j.engstruct.2017.03.012.

[21] Z. Li and Q. Ren "Development of a practical uniaxial cyclic constitutive model for concrete," in IOP Conf. Ser.: Earth Environ. Sci., vol. 295, pp. 1-10, Jul. 2019, https://doi.org/10.1088/1755-1315/295/4/042057.

[22] Y. H. Lee, K. Willam, and H. D. Kang "Experimental observations of concrete behavior under uniaxial compression," in Proceedings FRAMCOS-2, 1995, pp. 397-414.

[23] D. J. Carreira and K.-H. Chu, "Stress-strain relationship for plain concrete in compression," J. Am. Concr. Inst., vol. 82, no. 6, pp. 797-804, Nov. 1985, http://dx.doi.org/10.14359/10390.

[24] D. J. Carreira and K.-H. Chu, "Stress-strain relationship for reinforced concrete in tension," J. Am. Concr. Inst., vol. 83, no. 1, pp. 2128, Jan. 1986, http://dx.doi.org/10.14359/1756.

[25] T. Boone, P. A. Wawrzynek, and A. R. Ingraffea, "Simulation of the fracture process in rock with application to hydrofracturing," Int. J. Rock Mech. Min. Sci., vol. 23, no. 3, pp. 255-265, 1986, http://dx.doi.org/10.1016/0148-9062(86)90971-X.

[26] T. Boone and A. R. Ingraffea "Simulation of the fracture process at rock interfaces," in 4th Int. Conf. on Numerical Methods in Fracture Mec., 1987, pp. 519-531.

[27] Y. H. Lee and K. Willam, "Mechanical properties of concrete in uniaxial compression," ACI Mater. J., vol. 94, no. 6, pp. 457-471, Nov 1997, http://dx.doi.org/10.14359/329.

[28] J. J. C. Popovics, "A numerical approach to the complete stress-strain curve of concrete," Cement Concr. Res., vol. 3, no. 5, pp. 583599, Sep 1973, http://dx.doi.org/10.1016/0008-8846(73)90096-3.

[29] G. F. F. Bono "Modelos constitutivos para análise tridimensional de estruturas de concreto armado através do método dos elementos finitos,” Ph.D. dissertation, Dept. Civ. Eng., UFRGS, Porto Alegre, RS, 2008. [Online]. Available: https://lume.ufrgs.br.

[30] H. O. Korsal, T. Turgay, C. Karakoç, and S. Ayçenk, "Modeling aspects concerning the axial behavior of RC columns," WIT Trans. Eng. Sci., vol. 72, pp. 175-183, 2011, http://dx.doi.org/10.2495/MC110161.

[31] B. Y. Bahn "Behavior of concrete and slender reinforced concrete columns under cyclic axial compression with bidirectional eccentricities," Ph.D. dissertation, Dept. Civ. Env. Eng., NJIT, Newwark, NJ, 1994. [Online]. Available: https://digitalcommons.njit.edu.

[32] S. S. Penna "Formulação multipontecial para modelos de degradação elástica - Unificação teórica, proposta de novo modelo, implementação computacional e modelagem de estruturas de concreto," Ph.D. dissertation, Dept. Struct. Eng., UFMG, Belo Horizonte, MG, 2011. [Online]. Available: http://www.pos.dees.ufmg.br.

[33] J.-L. Batoz and G. Dhat, "Incremental displacement algorithms for nonlinear problems," Int. J. Numer. Methods Eng., vol. 14, pp. 1262-1267, 1979, http://dx.doi.org/10.1002/nme.1620140811.

[34] D. Ngo and A. C. Scordelis, "Finite element analysis of reinforced concrete beams," J. Am. Concr. Inst., vol. 64, no. 3, pp. 152-163, Mar. 1967, http://dx.doi.org/10.14359/7551.

[35] R. de Borst and M. A. Gutiérrez, "A unified framework for concrete damage and fracture models including size effects," Int. J. Fract., vol. 95, pp. 261-277, Jan. 1999, http://dx.doi.org/10.1023/A:1018664705895.

[36] R. de Borst, "Fracture in quasi-brittle materials: a review of continuum damage-based approaches," Eng. Fract. Mech., vol. 69, no. 2, pp. 95-112, Jan. 2002, http://dx.doi.org/10.1016/S0013-7944(01)00082-0.

[37] I. Carol, E. Rizzi, and K. Willam, "A unified theory of elastic degradation and damage based on a loading surface," Int. J. Solids Struct., vol. 31, no. 20, pp. 2835-2865, Oct. 1994, http://dx.doi.org/10.1016/0020-7683(94)90072-8.

[38] I. Carol, E. Rizzi, and K. Willam, "On the formulation of anisotropic elastic degradation. I. Theory based on a pseudo-logarithmic damage tensor rate," Int. J. Solids Struct., vol. 38, no. 4, pp. 491-518, Jan. 2001, http://dx.doi.org/10.1016/S0020-7683(00)00030-5.

[39] I. Carol, E. Rizzi, and K. Willam, "On the formulation of anisotropic elastic degradation. II. Generalized pseudo-Rankine model for tensile damage," Int. J. Solids Struct., vol. 38, no. 4, pp. 519-546, Jan. 2001, http://dx.doi.org/10.1016/S0020-7683(00)00031-7.

[40] L. R. S. Pereira, "Formulação de modelos de dano tensorial para análise fisicamente não linear de estruturas de concreto submetidas a carregamentos monotônicos e cíclicos,” M. S. thesis, Dept. Struct. Eng., UFMG, Belo Horizonte, MG, 2020. [Online]. Available: http://www.pos.dees.ufmg.br.

[41] M. Kwon and E. Spacone, "Three-dimensional finite element analyses of reinforced concrete columns," Comput. Struc., vol. 80, no. 2, pp. 199-2021, 2002, http://dx.doi.org/10.1016/S0045-7949(01)00155-9.

[42] V. Gopalaratnam and S. Shah, "Softening response of plain concrete in direct tension," ACI J. Proc., vol. 82, no. 3, pp. 310-323, May. 1985, http://dx.doi.org/10.14359/10338.

[43] J. K. Wight and J. G. MacGregor, Reinforced Concrete-Mechanics and Design, 6th ed. New Jersey, US: Pearson, 2012. 
[44] Federation International Du Beton, FIB Model Code for Concrete Structures, 2010.

[45] Associação Brasileira de Normas Técnicas, Projeto de Estruturas De Concreto - Procedimento, NBR 6118, 2014.

[46] Z. P. Bažant and G. Pijaudier-Cabot, "Measurement of characteristic length of nonlocal continuum," J. Eng. Mech., vol. 115, no. 4, pp. 755-767, 1989, http://dx.doi.org/10.1061/(ASCE)0733-9399(1989)115:4(755).

[47] D. L. Araújo, L. C. Carmo, F. G. T. Nunes, and R. D. Toledo Fo., "Computational modeling of steel fiber reinforced concrete beams subjected to shear," Rev. IBRACON Estrut. Mater., vol. 3, no. 1, pp. 68-94, 2010, http://dx.doi.org/10.1590/S198341952010000100005.

[48]D. A. Hordijk "Local approach to fatigue of concrete," Ph.D. dissertation, TU Delft, Delft, ZH, 1991. [Online]. Available: https://repository.tudelft.nl.

Author contributions: LRSP, SSP: computer programming, conceptualization, methodology, writing, formal analysis.

Editors: Osvaldo Manzoli, Guilherme Aris Parsekian. 